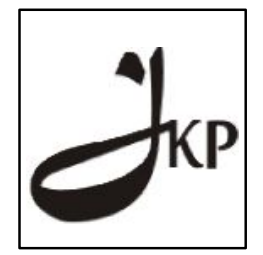

Jurnal Konseling dan Pendidikan

ISSN Cetak: 2337-6740 - ISSN Online: 2337-6880

http://jurnal.konselingindonesia.com

Volume 2 Nomor 1, Februari , HIm 49-53

Info Artikel:

Diterima 08/01/2014

Direvisi 12/01/2014

Dipublikasikan 28/02/2014

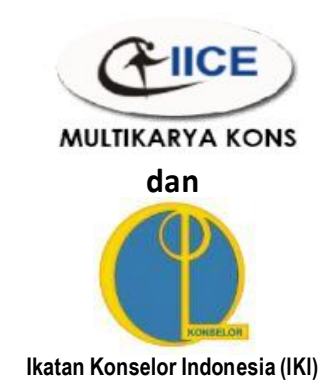

\title{
Peranan Kauselor dalam Perkhidmatan Kaunseling Pasca Bencana di Indonesia
}

\author{
Ifdil $^{1} \&$ Faizah Abd Ghani ${ }^{2}$ \\ ${ }^{1}$ Universitas Negeri Padang \\ ${ }^{2}$ Universiti Teknologi Malaysia \\ *) Corresponding author, $\ggg$ e-mail: ifdil@konselor.org
}

Abstract

Indonesia merupakan salah sebuah negara di dunia yang paling terdedah kepada bencana alam yang mengakibat pelbagai kerosakan muka bumi, kemusnahan harta benda di samping mendatangkan kecerderaan fizikal serta gangguan emosi dan psikologi. Keadaan ini jika tidak ditangani dengan kaedah yang tepat boleh mendatangkan masalah kesihatan mental dan psikososial di kalangan mangsa bencana. Kajian kuantitatif deskriptif ini bertujuan untuk melihat profil kaunselor, peranan, pengetahuan, dan minat dalam mengendalikan perkhidmatan kaunseling pasca bencana. Hasil kajian mendapati bahawa 69\%, responden pernah terlibat dalam kaunseling pasca bencana manakala $58.6 \%$ tidak mempunyai latihan asas dalam kaunseling pasca bencana. Dapatan kajian juga mendapati $100 \%$ responden berminat dan memerlukan latihan khusus dalam memberi perkhidmatan kaunseling pasca bencana. Implikasi dari kajian ini seterusnya membincangkan peranan kaunselor dalam perkhidmatan kaunseling pasca bencana, keperluan garis panduan dan latihan khusus kaunseling pasca bencana di Indonesia.

Keyword: Kaunseling pasca bencana, kesihatan mental, kemurungan, kebimbangan, tekanan, Post Traumatic Stress Disorder \& bencana

Copyright ( 2014 IICE - Multikarya Kons (Padang - Indonesia) dan IKI - Ikatan Konselor Indonesia - All Rights Reserved - Indonesian Institute for Counseling and Education (IICE) Multikarya Kons

\section{PENDAHULUAN}

Perkembangan bimbingan dan kaunseling di Indonesia bermula di seting sekolah pada awal tahun 1960 (J.T. Lobby Loekmono. 2000). Perkhidmatan kaunseling semakin berkembang, dengan wujudnya Program Pendidikan Profesi Konselor (PPK) di Universitas Negeri Padang pada tahun 1999/2000. (BK UNP, 2011). Program ini mendedahkan para kaunselor, untuk menjalan perkhidmatan yang pelbagai di luar seting sekolah, disamping untuk melayakkan kaunselor untuk berdaftar dan mendapatkan sijil perakuan amalan secara profesional.

Peranan kaunselor di Indonesia semakin berkembang selepas tahun 2000, dimana peranan kaunselor tidak hanya terbatas di seting sekolah tetapi telah merangkumi perkhidmatan kaunseling komuniti, seperti membantu mangsa pasca bencana alam. Perkhidmatan pasca bencana bermula selepas bencana tsunami di Aceh tahun 2004 (UNP, 2005). Dimana para kaunselor dari Universitas Negeri Padang telah memberikan perkhidmatan kaunseling di lokasi dimana bencana belaku pada minggu kedua. (UNP 2005). Dan seterusnya dikuti oleh pasukan dari institusi-institusi pengajian tinggi di Indonesia. Selain itu perkhidmatan kaunseling pasca bencana ini diteruskan pada selepas berlaku gempa bumi 2009 di Sumatera Barat, dimana kaunselor, pelajar kaunselor telah di hantar ke 50 lokasi dimana berlaku bencana gempa bumi di daerah Sumatera Barat. Pada tahun 2010 di Jogyakarta berlaku bencana gunung berapi, dimana para ahli Ikatan Konselor Indonesia (IKI) daerah Jawa Tengah, bersama dengan pelajar kaunselor Universitas Negeri Semarang telah terlibatkan diri dalam perkhidmatan kaunseling pasca bencana. Ifdil (2010) perkhidmatan kaunseling yang ditawarkan lebih memfokus kepada mengatasi an-efectife daily living. Perkhidmatan ini telah menggambarkan bahawa peranan kaunselor semakin diperlukan. 


\section{LATAR BELAKANG}

Indonesia merupakan salah sebuah negara di dunia yang paling terdedah kepada bencana alam (Deny Hidayati, Haryadi Permana, Krishna Pribadi, Febrin Ismail, Koen Meyers, Widayatun, et al. 2006: Budi Astuti. 2006; Imam AS. 2008; Yulia Ayriza. 2009), seperti gempa bumi, tsunami, banjir, tanah runtuh, gunung berapi, kemarau, angin taupan, dan lain-lain. Dalam masa 5 tahun (2005-2010) terakhir bencana alam di Indonesia telah berlaku sebanyak 4.408 kali (Badan NPB, 2010), dimana banjir merupakan bencana yang paling kerap berlaku (1.916), diikuti kekeringan (1.083) dan angin taupan sebanyak 580 walau bagaimana pun becana gempa dan stunami telah mengakibatkan banyak mangsa menghadapi masalah kecerderaan fizikal dan masalah psikologi. Mengikut kepada statistik. Hidayat (2009), mendapati 60\% mangsa mengalami stres selepas peristiwa gempa bumi di kabupaten Padang Pariaman, Sumatera Barat. Seterusnya Hasanuddin (2005) menyatakan bahawa trauma khusus, akibat bencana alam sebanyak 9,1\%. Mana kala Nandang Rusmana (2008) mendapati $77,1 \%$ pelajar Sekolah Rendah Islam masih dibayangi oleh peristiwa traumatik, 46,7\% berfikir negatif, 33,3\% merasa tidak berdaya, 34,8 $\%$ mempunyai masalah emosional dan $22,9 \%$, mengasingkan diri, sementara $16,7 \%$ mangsa merasa tidak ada masa hadapan.

Kekerapan bencana alam khususnya di Indonesia menimbulkan kecemasan, ketakutan, kerosakkan serta kerugian harta benda (Mudjiran, 2010). Selain itu bencana alam mengakibatkan mangsa merasa cemas, kebimbangan, stress (Taufik, T., \& Ifdil, I., 2013)., tidak tenteram, trauma dan somatization. (Diaz, Murthy, \& Lakshminarayana. 2006, Ratih 2007, Diah 2012). Masalah ini jika dibiarkan menurut Sunardi (2007) dapat mengakibatkan Post Traumatic Stress Disorder (PTSD) dalam masa 30 tahun atau boleh belaku sehingga sepanjang hayat.

Memandangkan implikasi dari peristiwa bencana banyak mendatangkan masalah kepada mangsa terutama emosi dan psikologi maka perkhidmatan kaunseling pasca bencana amat diperlukan. Resiliensi amat perlu ditingkatkan (Ifdil, I., \& Taufik, T., 2012). Apalagi dikalangan pelajar yang memiliki aras resiliensi yang rendah (Ifdil, I., Ardi, Z., \& Yendi, F., 2012): Ifdil, I., Ardi, Z., \& Yendi, F. M. ,2012).. Menurut ACA (American Counseling Association; 2010) menyatakan bahawa perkhidmatan kaunseling dalam menangani masalah pasca bencana merupakan salah satu fokus baru yang memerlukan kaunselor yang terlatih khusus dalam kaunseling. Kenyataan ini disokong oleh Ifdil, \& Faizah Abd Ghani (2012) yang menyatakan perkhidmatan kaunseling pasca bencana, boleh membantu menangani masalah kesihatan mental.

\section{PERNYATAAN MASALAH}

Menurut Mudjiharto (2010) menyatakan bahawa gangguan kesihatan mental berlaku selepas bencana walau bagaimanapun perkhidmatan yang dikendalikan selama ini lebih memfokuskan pada masalah kecerderaan fizikal pada mangsa dan membangun semula kemusnahan harta benda berbanding masalah kesihatan mental. Manakala Yulia Ayriza (2009) menyatakan bahawa perkhidmatan bencana yang sedia ada di Indonesia kurang melibatkan masyarakat secara aktif, terutamanya yang melibatkan para profesional. Ini menunjukkan bahawa peranan kaunselor di Indonesia belum terlibat secara profesional dan optimal dalam perkhidmatan pasca bencana. Seperti mana yang dinyatakan oleh Ifdil (2012a) bahawa penglibatan kaunselor di Indonesia masih rendah bila dibandingkan dengan kekerapan bencana yang terjadi di Indonesia. Oleh yang demikian kajian ini dijalankan untuk melihat profil kaunselor, peranan, pengetahuan dan minat dalam mengendalikan perkhidmatan kaunseling pasca bencana.

\section{METODOLOGI}

Kajian ini merupakan kajian kuantitatif deskriptif dengan melibatkan 29 kaunselor yang mewakili kaunselor dari Sumatera, Jawa, Bali, Nusatenggara Barat, Nusa Tenggara Timur, Kalimatan, Sulawesi dan Gorontalo. Soal selidik telah digunakan untuk mendapatkan profil kaunselor, peranan, pengetahuan, dan minat dalam mengendalikan perkhidmatan kaunseling pasca bencana serta mengenal pasti isu-isu berkaitan perkhidmatan perlaksanaan kaunseling pasca bencana.

\section{DAPATAN KAJIAN DAN PERBINCANGAN}

Hasil kajian menunjukkan bahawa 55,2\% responden laki-laki dan $44.8 \%$ perempuan, manakala keseluruhan responden berkelulusan ijazah Pendidikan Profesi Kaunselor (PPK). Sementara 31\% hanya berkelulusan PPK sahaja, semetara manakala 58\% juga memiliki ijazah Master kaunseling dan 10.3\% responden mempunyai ijazah 
program doktor dari universiti tempatan. Manakala keseluruhan responden berdaftar pada Ikatan Kaunselor Indonesia dan hanya $13.8 \%$ sahaja yang mempunyai sijil perakuan amalan, walau bagaimanapun 27,6\% dalam masa mengurusi sijil perakuan amalan. Dari segi tempoh pekhidmatan $20.7 \%$ berkhidmat kurang dari satu tahun, 58.6 berkhidmat 1-ke 5 tahun, manakala $13.8 \%$ lagi 6 ke 10 tahun dan hanya $6.9 \%$ responden berkhidmat lebih dari 21 tahun.

Seterusnya, dapatan kajian juga mendapati bahawa keseluruhan responden mengaku tahu tentang perkhidmatan kaunseling pasca bencana dan mampu menyenaraikan impak psikologi yang berlaku selepas bencana. Manakala 66\% dari responden menyatakan trauma merupakan impak terbesar selepas bencana, kecemasan $48 \%$ responden menyatakan, manakala stess $45 \%$ responden, depresi 38\% responden, ketakutan 38\% responden, kebimbangan $31 \%$ responden, manakala kekhawatiran, kesedihan, 6,9\% responden, dan gangguan semosional lain dengan min 3,4\% dari pada responden yaitu halusinasi, hysteria, insomnia, gila, frustasi, kekecewaan, marah, neorosis, pasrah, pendiam, phobia dan waspada.

Dapatan kajian mendapati 69\% responden pernah terlibat dalam kaunseling pasca bencana, manakala $58.6 \%$ menyatakan belum pernah menjalani latihan asas, sementara $41.4 \%$ responden pernah menjalani latihan, dari 41.4 $\%$ ini hanya $81.8 \%$ menyatakan mereka menjalani latihan secara asas sahaja dan $18.2 \%$ telah menjalani latihan secara sederhana, dimana tidak seorang responden mengaku menjalani latihan secara profesional. Latihan-latihan yang dijalankan selama ini hanya bersifat insedentil sahaja, seperti mana yang dinyatakan Budi Astuti (2006) Universiti Negeri Yogyakarta melakukan latihan untuk sukarelawan bagi menghadapi gempa melalui training of trainer, life reconstruction, menyediakan fasiliti dan tempat bermain bagi kanak-kanak, pelatihan brain storming, dan lain-lain. Selain dari pada itu, Antara News (2009) melaporkan bahawa seramai 80 orang pemuda mengikuti pelatihan berkaitan dengan traumatik kaunseling di Padang. Seterusnya UNP (2005, 2010), pelatihan yang dijalankan selama ini belum professional dan hanya memfokus pada pengetahuan asas serta latihan terapi bermain untuk mangsa kanak-kanak.

Dapatan juga menunjukkan bahawa 31\% kaunselor belum pernah menyertai dalam kaunseling pasca bencana, dimana majority responden adalah terdiri dari kaunselor yang baru menyelesaikan Program Profesi Kaunselor dan berdaftar kurang dari 5 tahun.

Selain dari pada itu dapatan juga menunjukkan peratusan penglibatan kaunselor menurut Fasa dalam perkhidmatan kaunseling pasca bencana seperti yang dinyatakan pada Jadual 1.1

Jadual. 1.1 Peratusan penglibatan kaunselor menurut Fasa dalam Perkhidmatan Kaunseling Pasca Bencana

Fasa Perkhidmatan Pasca Bencana

Pernah

Tidak

Fasa I (1-3 Hari)

Fasa II (3-10 Hari)

Fasa III (10 hari lebih)

Fasa IV (4 Bulan lebih)

$40 \% \quad 60 \%$

$\begin{array}{lll}70 & 30 & \%\end{array}$

$\begin{array}{llll}70 & \% & 30 & \%\end{array}$

$35 \%$

$65 \%$

Berdasarkan Jadual 1.1 menunjukkan peratusan penglibatan kaunselor menurut Fasa dalam perkhidmatan kaunseling pasca bencana, dimana perkhidmatan kaunseling yang dilakukan responden pasca bencana di Indonesia menumpu pada Fasa II dan III, seramai $70 \%$ kaunselor terlibat pada Fasa ini, walau bagaimanapun pada Fasa I hanya $40 \%$ pernah dan $60 \%$ tidak pernah, sementara itu pada Fasa IV seramai $65 \%$ tidak pernah manakalah $35 \%$ menyatakan pernah terlibat dalam perkhidmatan kaunseling pasca bencana. Hasil dapatan kajian ini selari dengan perkhidmatan yang dijalankan para kaunselor dari Universitas Negeri Padang, dimana telah memberikan perkhidmatan kaunseling di lokasi dimana bencana belaku pada minggu kedua. (UNP 2005), dan seterusnya dikuti oleh pasukan dari institusi-institusi pengajian tinggi di Indonesia. Walau bagaimanapun perkhidmatan kaunseling pada Fasa I harus diambil berat, Down, (2012) menyebutkan perkhidmatan pada Fasa I bencana diperlukan bagi mengurangi impak psikologi berterusan. Seterusnya Young, Ruzek, Wong, Salzer, \& Naturale (2005) menyatakan bahawa kondisi sebelum, saat dan setelah bencana mempengaruhi perkembangan PTSD dan gejala negatif lainnya dalam konteks bencana. Jika pada Fasa IV tidak ditangani boleh membawa impak negative yang berketerusan. 
Sesuai apa yang dikemukakan oleh Sunardi (2007) dapat mengakibatkan Post Traumatic Stress Disorder (PTSD) dalam masa 30 tahun atau boleh belaku sehingga sepanjang hayat.

Selain dari pada itu dapatan juga menunjukkan keseluruhan responden menyatakan bahawa bersetuju perlu menguasai kemahiran asas dalam kaunseling pasca bencana dan berminat dalam perkhidmatan kaunseling pasca bencana. Hal ini sesuai dengan kenyataan yang mengatakan kaunselor yang tinggal lokasi lebih cenderung untuk menyumbang dalam memberikan perkhidamatan kaunseling selepas bencana. Keadaan ini bersesuaian dengan situasi di Indonesia dimana kaunselor sepatutnya turut serta dalam perkhidmatan kaunseling pasca bencana.

Kajian ini juga mendapati bahawa keseluruhan responden mengatakan perlu mengikuti latihan guna mendapatkan kemahiran kaunseling pasca bencana. Sementara $93.1 \%$ kaunselor bersetuju perlunya satu garis panduan yang piawai berbentuk modul, di samping latihan khusus dalam bidang kaunseling pasca bencana bagi meningkatkan pengetahuan dan profesionalisme dalam melakukan pengkhidmat kaunseling selepas bencana. Young, et. All (2005), menyatakan bahawa untuk menguasai kompetensi dalam pengendalian kesihatan mental pada konteks pasca bencana, mestilah melalui latihan dengan menggunakan pendekatan modul. Hal ini menunjukan bahawa modul untuk melatih kaunselor di Indonesia untuk mengendalikan kaunseling selepas bencana berlu dibangunkan.

\section{LIMITASI KAJIAN}

Hasil kajian ini tidak boleh digeneralisasikan, karana kajian ini hanya dijalankan kepada bilangan responden yang kecil dan tidak mewakili keseluruhan populasi. Kajian lanjut harus dijalankan bagi mengenal pasti kompetensi kaunselor dalam perkhidmatan kaunseling pasca bencana.

\section{KESIMPULAN}

Kajian ini telah mengenal pasti profil kaunselor, peranan, pengetahuan, dan minat dalam mengendalikan perkhidmatan kaunseling pasca bencana. Keterlibatan kaunselor dalam perkhidmatan tolong bantu pasca bencana selama ini tanpa mengikuti latihan asas merupakan perkara yang amat memprihatinkan mana kala ini bermakna bahawa peranan kaunselor masih perlu dioptimalkan. Kajian ini juga mendapati bahawa keseluruhan kaunselor bersetuju agar disediakan garis panduan yang piawai dan latihan khusus untuk kaunselor bagi menjalankan kaunseling pasca bencana.

\section{Acknowledgments}

Terimakasih kepada pihak fakulti Pendidikan University Teknologi Malaysia dan pihak jurusan Bimbingan dan Kaunseling Universitas Negeri Padang, para kaunselor Ikatan Konselor Indonesia serta semua pihak yang telah membantu penulis melakukkan penyelidikan ini. Kerta kerja ini dibentangkan pertama kali pada persidangan antar bangsa dan pertandingan Inovasi Kauseling dan Pendidikan 2013, 6- Mac 2013, Dewan Tunku Ibrahim Ismail, UTHM - Johor Malaysia

\section{RUJUKAN}

ACA. 2011. Disaster Mental Health. Retrived November 29, 2011, from http://www.counseling.org/sub/dmh/index.aspx:

Antara. 2009. 80 Pemuda Ikuti Peltiahan Traumatik Kaunseling Retrieved 15 Februari 2013, 2013, from http://www.antarasumbar.com/berita/propinsi/d/1/41799/80-pemuda-ikuti-pelatihan-traumatik-kaunseling.html

Badan Nasional Penanggulangan Bencana BNPB 2010. Statistik Bencana. Retrived November 30, 2011, from www.bnpb.go.id

BK UNP. 2011. Pedoman Penyelenggaraan Program Profesi Konselor. Padang : Jurusan BK FIP UNP

Budi Astuti. 2006. Layanan Bimbingan dan Kaunseling Bagi Mangsa Gempa Bumi di Yogyakarta Jurusan Psikologi Pendidikan dan Bimbingan, FIP UNY

Deny Hidayati, Haryadi Permana, et al. 2006. Kajian Kesiapsiagaan Masyarakat dalam Mengantisipasi Bencana Gempa Bumi \& Tsunami: Lembaga Ilmu Pengetahuan Indonesia.

Diah Setia Utami. 2012. Bencana Alam dan Sosial Tingkatkan Gangguan Jiwa. Retrieved 28 Oktober 2012, from http://www.tempo.co/read/news/2012/08/31/173426684/Bencana-Alam-dan-Sosial-Tingkatkan-Gangguan-Jiwa 
Diaz, J. O. P., Murthy, S., \& Lakshminarayana, R. 2006. Advances in Psychological and Social Support after Disasters. New Delhi: Voluntary Health Association of India Press.

Ifdil, \& Faizah Abd Ghani. 2012. Pelayanan Kaunseling Kesehatan Mental Pasca Bencana di Indonesia Paper presented at the Seminar International Kaunseling MALINDO-2, Padang.

Ifdil, I., \& Taufik, T. (2012). Urgensi Peningkatan dan Pengembangan Resiliensi Siswa di Sumatera Barat. Pedagogi, $12(2), 115-121$.

Ifdil, I., Ardi, Z., \& Yendi, F. (2012). Tingkat Resiliensi Siswa SMA Negeri Pasca Bencana di Kota Padang.

Ifdil, I., Ardi, Z., \& Yendi, F. M. (2012). Resilience Post-Disaster of Students SMA Negeri in Padang. Konselor, 1(1).

Ifdil. 2010. PPK UNNES Bersama IKI Jawa Tengah Siapkan Diri untuk Kaunseling Trauma Merapi. Retrived November 29 Oktober 2012. From http://konselor.org/index.php?option=com_content\&task=view\&id=61\&Itemid=1

Ifdil. 2012a, 14 Januari 2012. Pelayanan Kaunseling Pasca Bencana Paper presented at the International Seminar of Guidance and Counseling, Padang.

Imam A. Sadisun. 2008. Pemahaman Karakteristik Bencana, Aspek Fundamental dalam Upaya Mitigasi dan Penanganan Tanggap Darurat Bencana. Paper. Bandung. Institut Teknologi Bandung

J.T. Lobby Loekmono. 2000. Guidance and Counseling in Indonesia. In Abdul Halim Otman \& A. Awang (Eds.), Counseling In the Asia-Pasifik Region (PB Gpg). USA: Greenwood Press.

Mudjiharto. 2010. Konsep Manajemen Bencana di Indonesia. Paper presented at the Seminar Nasional "Manajemen Bencana di Indonesia : Perspektif Promosi Kesehatan dan Psikologi”.

Mudjiran, Daharnis, Taufik, et al 2010. Pemulihan Dini Mental Masyarakat Pasca Gempa di Kota Padang. Padang: Pemko Padang, BNPB, UNP.

Priyadi Kardono, Hermana, et al. 2009. Data Bencana Indonesia Tahun 2009. Jakarta: Badan Nasional Penanggulangan Bencana (BNPB).

Ratih Putri Pratiwi. 2007. Sumbangan Psikologi Klinis Dalam Assessment Gangguan Psikologi Mangsa Bencana Alam. Retrived November 28, 2011, from http://psikologi.or.id/:

Sunardi. 2007. Gangguan Stres Pasca Trauma (Post Traumatic Stress Disorder) dalam Perspektif Kaunseling. PLB FIP Universitas Pendidikan Indonesia. Bandung.

Taufik, T., \& Ifdil, I. (2013). Kondisi Stres Akademik Siswa SMA Negeri di Kota Padang. Jurnal Konseling dan Pendidikan, 1(2), 143-150.

UNP. 2005. Laporan Pelaksanaan Kaunseling Trauma di Propinsi Nangroe Aceh Darusalam. Padang : Jurusan BK FIP UNP

UNP. 2010. Laporan Pelaksanaan Kaunseling Trauma di Propinsi Sumatera Barat. Padang: Jurusan BK FIP UNP Young, B. H., Ruzek, J. I., Wong, M., Salzer, M. S., \& Naturale, A. J. (2005). Disaster mental health training. Interventions following mass violence and disasters: Strategies for mental health practice, 54.

Yulia Ayriza. 2009. Pengembangan Modul Bimbingan Pribadi Sosial Bagi Guru Bimbingan Kaunseling Untuk Menghadapi Bencana Alam. Jurnal Kependidikan, 39(Nomor 2, November 2009), 141-156. 